\title{
Does this patient have COVID-19? A practical guide for the internist
}

\author{
Lorenzo Bertolino $^{1} \mathbb{( D} \cdot$ Martina Vitrone $^{1} \cdot$ Emanuele Durante-Mangoni $^{1,2} \mathbb{C}$
}

Received: 15 April 2020 / Accepted: 12 May 2020 / Published online: 23 May 2020

(c) Società Italiana di Medicina Interna (SIMI) 2020

\begin{abstract}
Coronavirus disease 2019 (COVID-19) is currently causing a pandemic and will likely persist in endemic form in the foreseeable future. Physicians need to correctly approach this new disease, often representing a challenge in terms of differential diagnosis. Although COVID-19 lacks specific signs and symptoms, we believe internists should develop specific skills to recognize the disease, learning its 'semeiotic'. In this review article, we summarize the key clinical features that may guide in differentiating a COVID-19 case, requiring specific testing, from upper respiratory and/or influenza-like illnesses of other aetiology. We consider two different clinical settings, where availability of the different diagnostic strategies differs widely: outpatient and inpatient. Our reasoning highlights how challenging a balanced approach to a patient with fever and flu-like symptoms can be. At present, clinical workup of COVID-19 remains a hard task to accomplish. However, knowledge of the natural history of the disease may aid the internist in putting common and unspecific symptoms into the correct clinical context.
\end{abstract}

Keywords Signs $\cdot$ Symptoms $\cdot$ Differential diagnosis $\cdot$ Influenza-like illness $\cdot$ Respiratory tract infection

\section{Introduction and aims}

During the past few months, the novel Severe Acute Respiratory Syndrome Coronavirus 2 (SARS-CoV-2) outbreak evolved from a small cluster of atypical pneumonia of unknown origin into a global pandemic. Coronavirus disease 2019 (COVID-19) now affects over 200 countries with $>3,500,000$ confirmed cases and nearly 250,000 deaths worldwide [1, 2]. Italy is among the most severely involved countries, with 212,532 confirmed cases, 27,402 deaths and an observed lethality rate of $12.9 \%$, according to the most recent estimates of May 7 [3]. Such a high lethality has been related to several factors, including older age distribution, different definition of COVID-19-related deaths and testing strategies [4]. Indeed, these data are probably overestimated as incidence rates are likely underestimated. Among reasons

Emanuele Durante-Mangoni

emanuele.durante@unicampania.it

1 Department of Precision Medicine, Section of Internal Medicine, University of Campania 'L. Vanvitelli', Napoli, Italy

2 Unit of Infectious and Transplant Medicine, AORN Ospedali dei Colli-Monaldi Hospital, Piazzale E. Ruggieri, 80131 Naples, Italy for this epidemiologic scenario is the absence of homogeneous criteria for clinical recognition and testing of suspected cases and the uncertainty regarding prevalence of infection among asymptomatic/poorly symptomatic subjects.

While it is obvious that the virus will persist in endemic form after the pandemic phase has waned, physicians currently struggle with the need to correctly approach a new disease posing peculiar challenges in terms of differential diagnosis. This is mostly related to the lack of specific signs and symptoms that may guide clinicians to swiftly recognize, properly isolate and appropriately treat a COVID-19 case in the early phase of the disease natural history. Since COVID-19 will remain a challenge during the foreseeable future, we believe all internists should develop specific skills to recognize the disease, learning what we can refer to as the 'semeiotic' of this new disease.

In this article, we aimed at summarizing the key features that might guide the internist in differentiating a truly suspected COVID-19 case, requiring specific testing, from upper respiratory and/or influenza-like illnesses (ILIs) of other aetiology. In our opinion, this is pivotal for several reasons. First, to limit the further spread of the virus, a suspected case needs prompt isolation [5]. Second, any physician dealing with suspected COVID-19 cases requires personal protection equipment that should be used only when 
truly necessary [6]. Furthermore, while assessing a suspected case of COVID-19, physicians should not overlook other equally or even more serious diseases, which require adequate diagnosis and treatment. Lastly, the negative psychological consequences on family members and health care personnel that occur after detecting a suspected COVID-19 case should not be underestimated [7]. These considerations highlight how challenging a balanced approach to a patient with ILI can be today.

We consider two different clinical settings, where the availability of blood tests and imaging differs widely: outpatient (home, family doctor's office) and inpatient.

\section{COVID-19 in the outpatient setting}

As pandemic spread of SARS-CoV-2 progresses, it is inappropriate to still rely on epidemiologic features alone, including contact with a confirmed COVID-19 case, to suspect the disease. In contrast, any patient with fever or $\mathrm{ILI} /$ acute respiratory illness (ARI)/severe acute respiratory illness (SARI) should be clinically assessed for possible COVID-19, regardless of travel history or exposure. Since there are no specific COVID-19 signs and symptoms, relying on them to exclude the disease can be misleading. Nevertheless, medical history is essential in the evaluation and, as in any other clinical scenario, offers key clues. Therefore, a careful evaluation of patient symptoms is highly encouraged.

Concerning COVID-19, fever is reported as one of the most common symptoms, in several studies, ranging in prevalence between 76.5 and $98.6 \%$ [8-16]. Fever is rarely a stand-alone symptom, rather it associates with non-productive cough (in 50-70\% of cases) [8-16] and dyspnoea (in $30-60 \%$ of cases) [13]. At COVID-19 onset, cough is almost invariably non-productive [17-27], although it may subsequently evolve with sputum production in up to half of cases [9] when the disease progresses or a bacterial superinfection ensues. The prevalence of cough and dyspnoea appears to increase in patients who subsequently require intensive care support ( $88 \%$ for both) [28]. Thus, the two additional manifestations of cough and dyspnoea may also portend a prognostic significance, guiding the family doctor in the subsequent management steps. Fever and cough almost always occur at the same time, whereas dyspnea typically begins some 5-7 days later [9].

Other frequent symptoms are myalgia (31\%) [13] and fatigue (38\%) [12], that may be severe. Less common signs/ symptoms include headache (8\%) [10], diarrhoea (6.3\%) [13], nausea and vomiting (5.0\%) [12]. Worthy of mention are some neurological manifestations of COVID-19, such as anosmia, hyposmia and dysgeusia, even though few scientific data are available at present about their prevalence. In a Chinese study focused on neurological findings in 214 COVID-19 patients, hypogeusia and hyposmia were detected in $12(5.6 \%)$ and 11 (5.1\%) of them, respectively [29]. Three expert statements from the American, British and French associations of otorhinolaryngology also underline the importance of these sensory abnormalities. However, such professional body statements are largely based on emerging anecdotal and non-peer reviewed clinical observations [30].

Upper respiratory tract infection (URTI) symptoms, including nasal congestion or rhinorrhoea, appear to be seldom reported (4.8 and 4\%, respectively) [10, 12]. Similarly, other signs of URTI are also observed rarely: throat congestion (1.7-4\%), tonsil swelling (2.1\%) and lymph node enlargement $(0.2 \%)[11,12]$. Thus, the presence of these latter manifestations in a febrile patient could either point against COVID-19 or indicate a milder form of disease that does not tend to further evolve. Indeed, it is necessary to underline that the vast majority of these data comes from studies on hospitalized patients, both in and out of the intensive care unit (ICU), and very few reports have been generated on mild and non-admitted cases. Among the latter, the prevalence of URTI signs/symptoms may be much higher and, therefore, predict a more favourable outcome. Other symptoms, not specific to COVID-19, could be useful to early predict patient outcome. Indeed, Wang et al. showed that patients admitted to ICU had a statistically higher prevalence of anorexia, shortness of breath and dizziness [9].

In Table 1, we compare clinical presentation and outcome of COVID-19 [31] with those of SARS [32-34] and influenza A (H1N1 2009 outbreak) [35, 36], as examples of recent SARIs, and with common ILIs, including seasonal flu (H3N2) [37-40] and non-influenza acute respiratory illnesses [38, 39]. Since data of COVID-19 are largely preliminary and come from studies on mostly hospitalized patients, the prevalence of certain symptoms may differ from the real clinical spectrum of the disease, that is mostly comprised of mildly symptomatic and non-severe cases (around 80\%) [41], as for all disorders considered. For example, regarding influenza A, URTI signs and symptoms are much more common in community than hospitalized cases (Table 1). A similar trend may exist for COVID-19, but might be hidden by the different populations considered. Notwithstanding, the prevalence of URTI signs/symptoms remains much lower in COVID-19- than in H1N1-hospitalized cases. Furthermore, it is interesting to compare the COVID-19 clinical spectrum with that of diseases caused by more phylogenetically similar viruses. In fact, in the 2002-2003 SARS outbreak, there was a higher percentage of URTI signs/symptoms as well as a higher prevalence of gastrointestinal symptoms [32-34] (Table 1). This is most likely not due to a selection bias, as SARS studies largely enrolled hospitalized patients too. In conclusion, there is a paucity of information regarding the presence and epidemiological significance of mildly symptomatic and asymptomatic infection in SARS [42], as well as COVID-19. 
Table 1 Prevalence of different signs/symptoms among common viral illnesses compared with COVID-19 [31-41]

\begin{tabular}{|c|c|c|c|c|c|c|c|}
\hline & \multirow[t]{2}{*}{ COVID-19 } & \multirow[t]{2}{*}{ SARS } & \multicolumn{3}{|c|}{ Influenza A (H1N1 2009) } & \multirow{2}{*}{$\begin{array}{l}\text { Seasonal } \\
\text { Influenza }\end{array}$} & \multirow{2}{*}{$\begin{array}{l}\text { Non- } \\
\text { influenza } \\
\text { ARI }\end{array}$} \\
\hline & & & All & Community & Hospitalized & & \\
\hline Incubation period, days & $4-14$ & $2-10$ & $1.4-4$ & & & $1-5$ & $1-5$ \\
\hline Fever, $\%$ & $75.6-98.6$ & 99.3 & 84.7 & 81.8 & 85.8 & 94.3 & 87.5 \\
\hline Cough, $\%$ & 69.6 & 69.4 & 84.9 & 83 & 81.2 & 85.5 & 65.5 \\
\hline Shortness of breath, $\%$ & 45.6 & 41.7 & 31.2 & 14.8 & 51.6 & 9.8 & 8.6 \\
\hline Myalgia, \% & 31 & 49.3 & 58.1 & 59.5 & 23.6 & 76.3 & 72 \\
\hline Fatigue, $\%$ & 38 & NA & 25.3 & 6.9 & 18.4 & 81.6 & 77.7 \\
\hline Headache, $\%$ & 8 & 35.4 & 66.5 & 65.8 & 18.7 & 69 & 63 \\
\hline Rhinorrhea, \% & 4 & 22.5 & 60.1 & 59 & 25.7 & 76 & 55 \\
\hline Sore throat, $\%$ & 1.7 & 12.5 & 49.5 & 51.4 & 29.9 & 63.5 & 61.3 \\
\hline Diarrhoea, $\%$ & 6.3 & 23.6 & 13 & 11.2 & 14.5 & 15.3 & 17.2 \\
\hline Nausea and vomiting, \% & 5 & 19.4 & 19.9 & 22.2 & 11.3 & 41 & 29 \\
\hline Fatality rate, $\%$ & $1.8-3.4$ & 15 & 0.02 & & & 0.09 & NA \\
\hline Hospitalization rate, $\%$ & $20.7-31.4$ & NA & 8.2 & & & 1.38 & NA \\
\hline ICU admission, $\%$ & $4.9-11.5$ & 23.2 & $3.2-44$ & & & NA & NA \\
\hline Median age, years & NA & 39.3 & 18.1 & & & 28.9 & 31.27 \\
\hline
\end{tabular}

$N A$ not available
When approaching a patient with fever, searching for other signs/symptoms of organ involvement is of utmost importance. Undoubtedly, suspicion index of COVID-19 declines when the patient presents with recurrence of febrile illnesses related to prior known conditions, including urinary tract infections, exacerbations of chronic obstructive pulmonary disease and flares of immune-mediated conditions. If fever quickly responds to antibiotic therapy, COVID-19 should not be a concern. Therefore, it remains crucial to collect a comprehensive drug history on chronic and/or recently added medications. Indeed, fever of COVID-19 tends to persist for several days when the disease progresses towards more severe stages and does so despite any antibiotic therapy until resolution or progression [17-27].

As physical examination is concerned, there is a dramatic lack of data regarding the most common respiratory physical findings in SARS-CoV-2 pneumonia. Theoretically, COVID19 should mimic atypical pneumonia, being characterized by a clinical-radiological dissociation. Therefore, the absence of added sounds on lung auscultation should not rule out COVID-19 pneumonia. In contrast, pleural effusion is very rarely seen in COVID-19 (about 5\% of cases), especially in the early phase of the disease [43]. Given the lack of thoracic examination findings, clinicians should pay attention to any sign of acute or acute on chronic respiratory failure, such as central cyanosis, tachypnoea, use of accessory muscles, and should always assess peripheral oxygen saturation by means of a pulse oximeter. The timing of onset of respiratory distress is typical in COVID-19, and usually occurs between day 5 and day 7 of illness $[9,12]$. This is also the observed median outpatient-inpatient interval, equal to 6.8 days [8].

\section{Inpatient with suspected COVID-19}

The inpatient with COVID-19 may be admitted because of suggestive signs/symptoms or may develop them while in hospital for other reasons/conditions. Although more diagnostic resources are available in the hospital, clinicians must make the best use of them, to perform quick diagnoses while minimizing health care resource utilization. Available diagnostic tools are blood tests, nasal and throat swabs, serology and lung imaging (ultrasound and radiology).

The clinical features of COVID-19 in the inpatient are heterogeneous, ranging from an asymptomatic state to acute respiratory distress syndrome and multi-organ dysfunction. On admission to the hospital for COVID-19, the most common presenting symptoms remain fever, cough, dyspnoea, fatigue and myalgia [8-16]. Less common symptoms are headache, dizziness, sore throat, sputum production, diarrhoea, nausea and vomiting $[9,13]$. While it is rather simple to assess previously healthy patients, COVID-19 diagnosis may be more complex in those already hospitalized for other reasons, especially heart and lung disease. In these subjects, non-specific COVID-19 symptoms could be even more nuanced, especially in fragile, elderly, comorbid or immunocompromised patients, or overlap/be confused with those of concomitant disorders.

In the current epidemic time, when we face an inpatient with fever and/or new onset cough, with or without associated dyspnoea, the SARS-CoV-2 test on nasal swab should be immediately ordered. At the same time, all efforts should be directed at ruling out aetiologies other than SARS-CoV-2 through history, physical examination and routine laboratory 
tests. As a matter of fact, in the absence of specific treatment for COVID-19, the correct identification of alternative aetiologies is more likely to translate into an effective, targeted treatment. In the next future, when endemic spread of SARS-CoV-2 is likely to establish, COVID-19 suspicion should be based on the most common presenting signs of fever, cough, dyspnoea and malaise.

It is of crucial importance to understand that the current sensitivity of SARS-CoV-2 molecular tests is undetermined. Thus, in the current era, it is appropriate to use all available and specific molecular tests for bacteria and viruses on respiratory samples (throat swab/nasopharyngeal swab/ sputum/endotracheal aspirate or bronchoalveolar lavage). Bacterial and fungal cultures should also be obtained, as well as Pneumococcal and Legionella urinary antigen tests. Although positivity for another respiratory pathogen does not rule out COVID-19, an alternative diagnosis coupled with a first negative SARS-CoV-2 test on nasal swab tends to exclude COVID-19.

Regarding COVID-19 laboratory findings, those most commonly reported are hypoalbuminemia, elevated C-reactive protein and lactate dehydrogenase (LDH) serum levels, lymphopenia and high erythrocyte sedimentation rate [13]. Less commonly, there is elevation of alanine aminotransferase, aspartate aminotransferase, creatine kinase, and fibrinogen D-dimers. Zhou et al. showed that D-dimers $(>1 \mu \mathrm{g} / \mathrm{mL}$ ) were the only blood marker independently correlated to a worse outcome, together with age and a SOFA score between 6 and 14 [16]. Moreover, leukopenia, lymphopenia and D-dimers elevation are more prominent in severe cases [12]. In fact, SARS-CoV-2 mainly acts on T lymphocytes, triggering cytokine upregulation and immune stimulation that exhausts immune cells, finally blunting cellular immune responses. Damage to T lymphocytes may be an important factor leading to patient deterioration. The role of the immune system in COVID-19 is still undefined but cytokine storm syndromes and immunosuppression have been proposed among factors leading to death in these patients [44]. Concerning IL-6, higher blood levels of this cytokine correlate with a worse outcome [45].

Procalcitonin (PCT) may also be useful in patient evaluation. It does not appear substantially altered in COVID-19 early phase and on hospital admission, as is for other viral infections [9, 12]. Subsequent PCT increase may reflect bacterial superinfection and should be carefully considered for further diagnostic and therapeutic purposes [46]. Recent studies suggest that serial measurements of PCT showing increasing levels correlate with an unfavourable outcome [46]. Troponin I may also be abnormal in a minority of COVID-19 cases, with a significantly increased level in those with a more severe disease [47]. Similarly, NTproBNP seems to independently predict in-hospital death in severe COVID-19 patients [48].
In summary, the routine workup with hemato-chemical tests portends significant diagnostic information in suspected COVID-19 patients. Raised inflammatory markers and normal leukocyte count without neutrophilia tend to rule out bacterial infections, whereas lymphopenia suggests COVID-19.

Radiologic manifestations of SARS-CoV-2 infection are various and progress rapidly over the course of the disease. Chest X-ray is less sensitive and specific than CT scan and can be normal in the early phase. The most common patterns seen on chest $\mathrm{CT}$ are bilateral ground-glass opacity (GGO), smooth or irregular interlobular septal thickening, air bronchogram, crazy-paving pattern and thickening of the adjacent pleura. These lesions are mainly located peripherally and sub-pleural with diffuse, bilateral distribution. Less common CT findings include nodules, cystic changes, bronchiolar ectasia, pleural effusion and lymphadenopathy [9-11, 13, 14, 22, 26, 28]. Since COVID19-related patchy or confluent lesions tend to distribute peripherally and sub-pleural, lung ultrasound (LUS) has a major diagnostic role. LUS is non-invasive, safe, fast, low cost and can be repeated bedside to monitor evolution and the effects of therapies. Also, it may aid to optimize ventilation and weaning in the ICU setting [49] and reduces the need for patient movement within the hospital environment. However, LUS is unable to correctly identify pulmonary embolism or pulmonary arterial thrombosis that are emerging as common and prognostically relevant conditions in COVID-19, likely contributing to both severe respiratory failure and mortality [16].

Although detailed history, complete clinical evaluation and chest imaging are essential for COVID-19 diagnosis, the current diagnostic gold standard remains real-time reverse transcription polymerase chain reaction (rRT-PCR) on respiratory samples (nasal swabs, throat swabs, sputum or lower respiratory samples). Several studies report that sputum possesses the highest positivity rate (74.4-88.9\%), followed by nasal swabs (53.6-73.3\%) in both severe and mild cases during the first 14 days after illness onset. For samples collected $\geq 15$ days after onset, sputum and nasal swabs still showed a high positive rate ranging from 42.9 to $61.1 \%$. The positive rate of throat swabs collected after the 1 st week is low, especially in samples from mild cases. Conversely, viral RNA could be detected in all lower respiratory tract samples from severe, but not mild cases, after the first week of symptoms [50].

Viral load in asymptomatic subjects appears to overlap with that of symptomatic patients [51], suggesting at present no role for SARS-CoV-2 semi-quantitation in the clinical setting. The molecular method for SARS-CoV-2 detection can also provide false-negative results when either sample collection is not optimal or there is insufficient amount of viral genomes, for example in early and 
late stages of the disease. Moreover, certified laboratories, expensive equipment and trained personnel are required.

Very initial experience exists regarding SARS-CoV-2 serology. Detecting specific antibodies, especially IgM, which are produced rapidly after infection, can be a less expensive tool to combine with rRT-PCR to enhance detection sensitivity and accuracy. It seems that in the acute phase of COVID-19, anti-SARS-CoV-2 IgM and IgA antibodies are both detectable at a median time of 5 days after symptom onset, while IgG antibodies appear after a median time of 14 days [52]. Zhao et al. reported that combining RNA and antibody testing, especially total antibody measurement, sensitivity for detecting COVID-19 in the first week of disease raises significantly, up to $78.7 \%$ [53]. These findings suggest that serological tests could be an important complement to RNA detection during the illness course, although further studies are warranted [53].

Once diagnosed, COVID-19 risk stratification should be performed using nonspecific and specific risk scores. The MuLBSTA (multilobular infiltration, hypo-lymphocytosis, bacterial coinfection, smoking history, hypertension and age) score is a system that allows risk stratification of patients hospitalized with viral pneumonia. There are two risk categories, MuLBSTA 0-11 (low risk) and MuLBSTA 12-22 (high-risk), with a 90-day mortality of 5.07 and $33.92 \%$, respectively. Further investigation is needed to explore the applicability of the MuLBSTA score in predicting mortality risk in COVID-19 [54].

The National Early Warning Score (NEWS) is a scoring system that can be used in all hospitalized patients to allow for the early detection of clinical deterioration in acutely ill patients and the potential need for higher levels of care [55]. In 2017, the British National Health System endorsed the updated NEWS2 score that can be applied both in emergency and inpatient setting, for initial assessment and serial monitoring of patients [56]. This score is based on the measurement of six vital signs: respiratory rate, oxygen saturation, temperature, systolic blood pressure, heart rate and state of consciousness. Each parameter is graded in levels, to which a numerical value is assigned; the sum of numerical values provides a reliable measure of deviation from normal physiology. If oxygen supplementation is required, the score is increased by two points. Based on total score, there are three levels of clinical alert: a low level (NEWS2 0-4) requiring fast clinical evaluation by a competent nurse; a medium level (NEWS2 5-6), needing prompt appraisal by a skilled clinician; and a high level (NEWS2 $\geq 7$ ), necessitating emergency assessment of a critical care team [57]. However, as no studies have been done to validate the performance of NESW2 in defining the severity of illness or the evolution of COVID-19, the NEWS2 score should be used with caution in this specific setting.

\section{Conclusions}

COVID-19 is a new disease that will likely persist in the general population for a long time. Although changes in incidence and clinical presentation are possible and hard to be foreseen, we believe that all internal medicine physicians should develop clinical skills to adequately recognize COVID-19. This is true for both hospital-based physicians and those who practise in the community. A practical algorithm, valid for both clinical settings considered, that physicians could follow as a starting point, is presented in Fig. 1.

We admit that, at the present time, clinical workup of COVID-19 remains a hard task to accomplish. To provide a landscape of the variable presentation of COVID-19, we have summarized the major features of four recent cases we dealt with in our hospital (Fig. 2). As shown, dissociation between clinical features, diagnostic test results and response to treatment may occur, making COVID-19 management challenging. However, we have shown evidence to support the fact that knowledge of the natural history of the disease may aid the internist in putting common and unspecific symptoms into the correct clinical context. Internists should refrain from indiscriminate application of diagnostic tests, and should be guided by clinical observation and reasoning towards the best management practice patterns. Such a correct approach will improve health care resource utilization, minimize psychologic distress, adequately protect the community and convey the optimal care to the subset of COVID-19 patients with a more severe clinical course. 


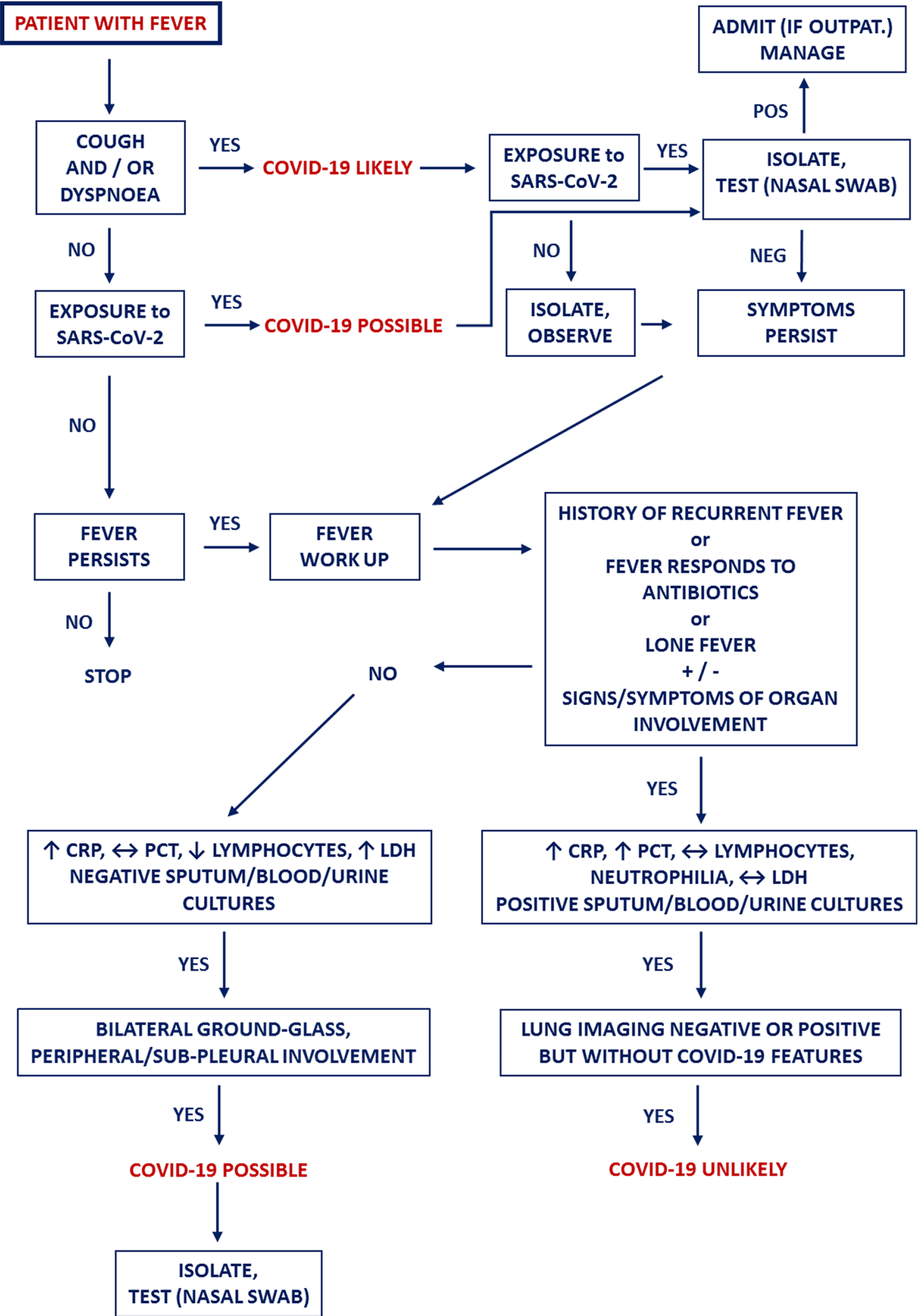

Fig. 1 Practical algorithm for the initial diagnostic approach to outpatients and inpatients with suspected COVID-19 


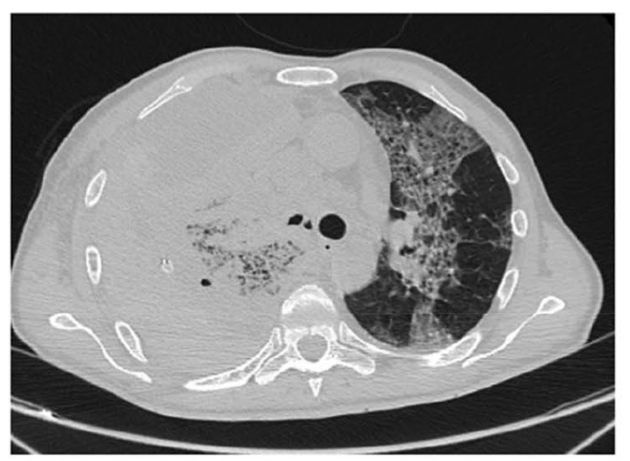

\section{CASE 1.}

56 year-old man with a history of advanced right lung cancer and massive ipsilateral pleural effusion. Admitted to our Hospital for worsening dyspnea and cough. No fever. Serial chest CT scan show de novo development of bilateral interstitial infiltrates, highly suggestive of COVID-19. RT-PCR on multiple nasal swabs as well as IgM and IgG assay for SARS-CoV-2 remained negative. Patient passed away over a few days.
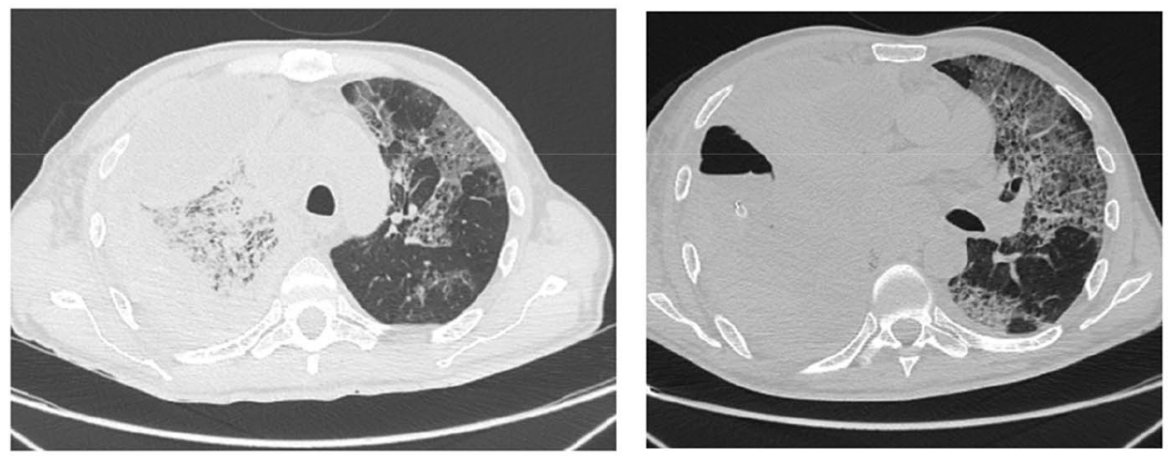

\section{Labs on admission:}

- WBC: 25870 cells $/ \mu \mathrm{L}$

- Neutrophils: 22400 cells $/ \mu \mathrm{L}$

- Lymphocytes: 1230 cells $/ \mu \mathrm{L}$

- Procalcitonin: $4.09 \mathrm{ng} / \mathrm{mL}$

- LDH: $571 \mathrm{U} / \mathrm{L}$

- CRP: $44.6 \mathrm{mg} / \mathrm{dL}$

- D-dimers: $215 \mathrm{ng} / \mathrm{mL}$

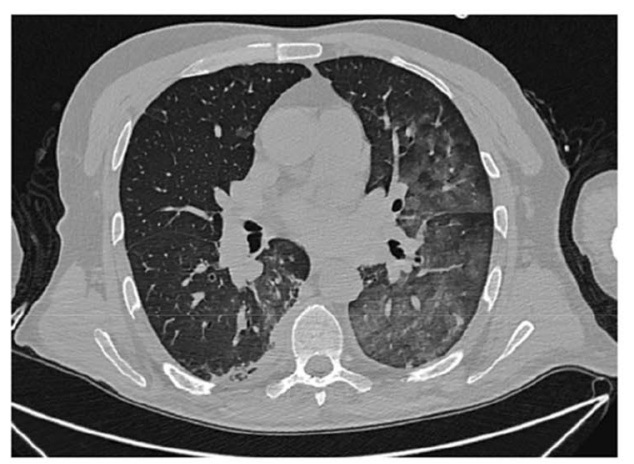

\section{CASE 2.}

42 year-old man on chronic hemodialysis with a history of fever of undefined duration and dry cough. On admission, CT shows bilateral interstitial pneumonia. Arterial blood gas analysis demonstrates acute hypoxemic respiratory failure. No signs or symptoms of heart failure. Ongoing therapy with iv ceftriaxone 2 gr/day. Results of RT-PCR on nasal swabs for SARS-CoV-2 are negative twice. The COVID-19 suspect is anyway high, and the patient remains isolated. However, fever responds to antibiotic therapy, making COVID-19 unlikely.
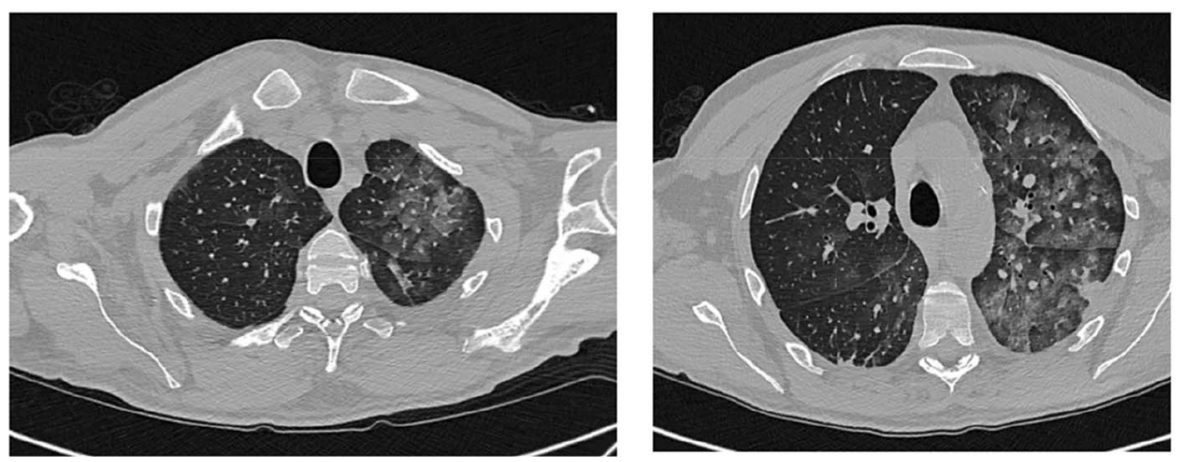

\section{Labs on admission:}

- WBC: 12420 cells $/ \mu \mathrm{L}$

- Neutrophils: 11480 cells $/ \mu \mathrm{L}$

- Lymphocytes: 670 cells/ $\mu \mathrm{L}$

- Procalcitonin: $21.1 \mathrm{ng} / \mathrm{mL}$

- LDH: $331 \mathrm{U} / \mathrm{L}$

- CRP: $20 \mathrm{mg} / \mathrm{dL}$

Fig. 2 Illustrative cases showing the challenges of suspected COVID-19 approach 


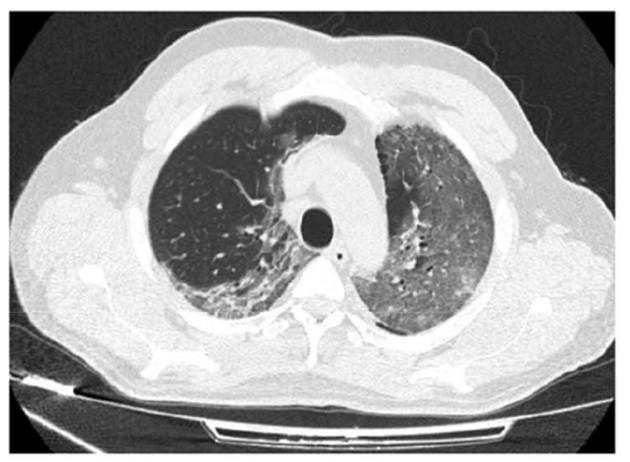

\section{CASE 3.}

57 year-old, previously healthy man with a 7 day history of fever and cough and a 1 day history of worsening shortness of breath. CT shows bilateral interstistial pneumonia. Arterial blood gas demonstrates acute hypoxemic respiratory failure. SARS-CoV-2 RT-PCR nasal swab is positive. Patient is admitted to our Hospital Intensive Care Unit (ICU) because of refractory hypoxemia and is mechanically ventilated for 2 weeks. Treated with tocilizumab, remdesivir and supportive care, is subsequently discharged from the ICU and is currently in stable conditions.
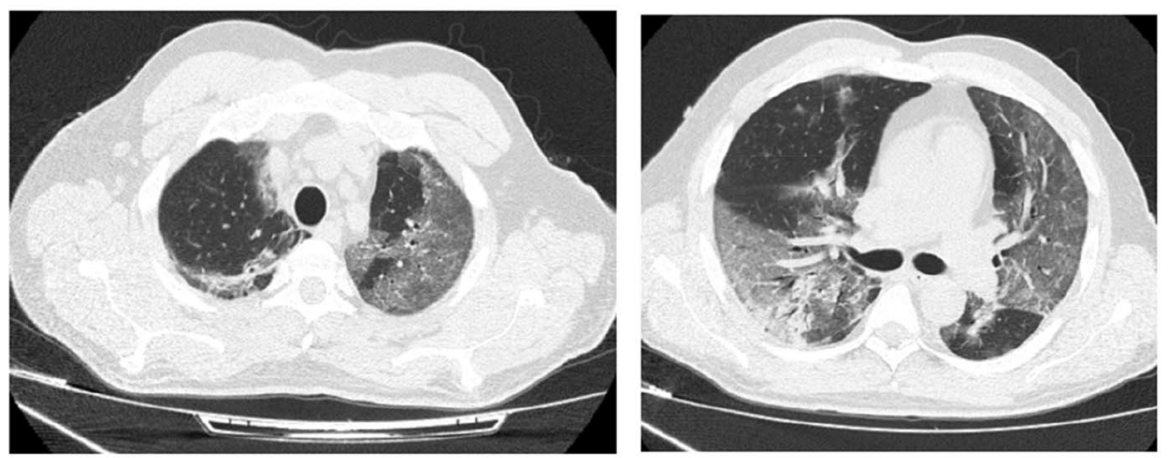

Labs on admission:

- WBC: 3650 cells/ $\mu \mathrm{L}$

- Neutrophils: 2930 cells $/ \mu \mathrm{L}$

- Lymphocytes: 750 cells/ $\mu \mathrm{L}$

- Procalcitonin: $0.27 \mathrm{ng} / \mathrm{mL}$

- LDH: $656 \mathrm{U} / \mathrm{L}$

- CRP: $13 \mathrm{mg} / \mathrm{dL}$

- D-dimers: $3230 \mathrm{ng} / \mathrm{mL}$

- IL-6: $78.6 \mathrm{pg} / \mathrm{mL}$

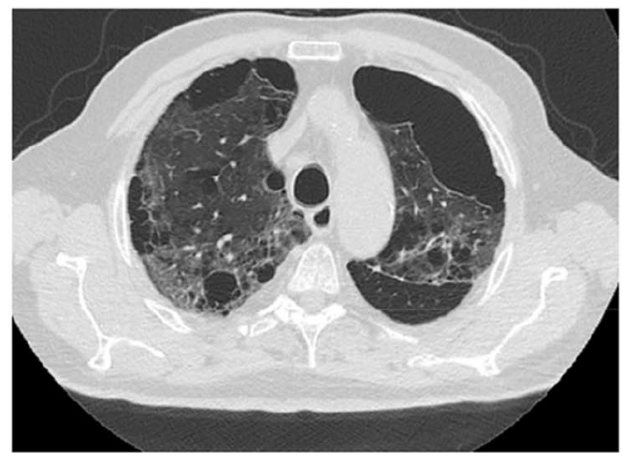

\section{CASE 4.}

A 79 year-old man with bullous emphysema and chronic obstructive pulmonary disease develops worsening dyspnea, without fever and cough, associated with myalgia and fatigue. Chest CT shows bilateral interstitial pneumonia. SARS-CoV-2 RT-PCR nasal swab is positive. Admitted to the Intensive Care Unit of our Hospital because of severe acute respiratory distress syndrome, he is put on invasive ventilation. Despite of immune modulating and antiviral therapy, the patient died on hospital day 11.
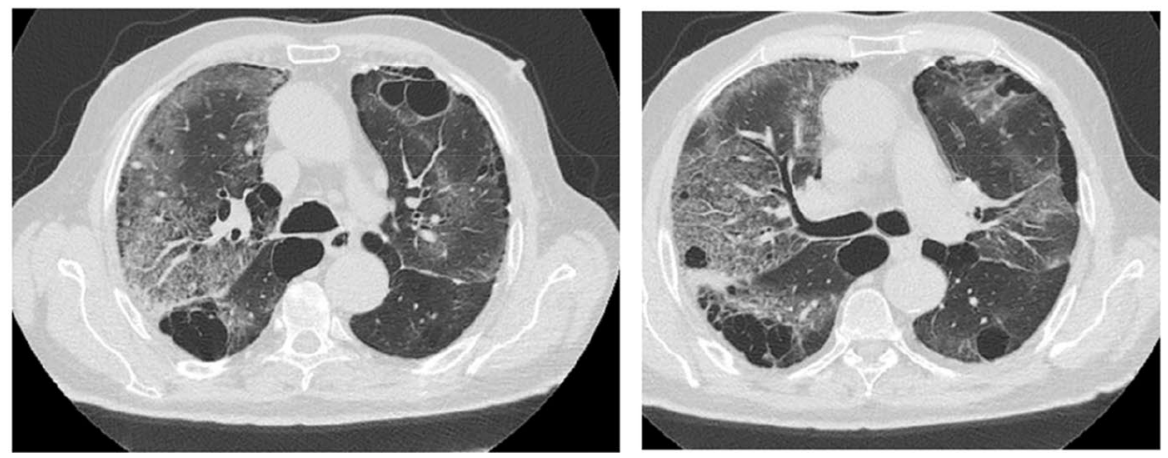

Labs on admission:

- WBC: 8350 cells $/ \mu \mathrm{L}$

- Neutrophils: 7280 cells/ $\mu \mathrm{L}$

- Lymphocytes: 680 cells $/ \mu \mathrm{L}$

- Procalcitonin: $0.11 \mathrm{ng} / \mathrm{mL}$

- LDH: $195 \mathrm{U} / \mathrm{L}$

- CRP: $8.5 \mathrm{mg} / \mathrm{dL}$

- IL-6: $95.6 \mathrm{pg} / \mathrm{mL}$

Fig. 2 (continued)

Author contributions LB, MV and EDM worked on concept of the work, data retrieval and interpretation, drafting and critical revision of the manuscript, and approved the final draft.

Funding No specific funding was obtained for this study.
Data availability All data are derived from the current literature.

\section{Compliance with ethical standards}

Conflict of interest None of the authors has any conflict of interest relevant to the content of this work. There are no competing interests. 
Ethical approval This work did not raise any ethical issue.

Statement of human and animal rights This article did not include original research involving human participants and/or animals.

Informed consent No informed consent could be obtained from the four patients described due to constraints in direct encounter.

\section{References}

1. World Health Organization Coronavirus disease (COVID-2019) situation reports. https://www.who.int/ emergencies/diseases/ novel-coronavirus-2019. Accessed 7 May 2020

2. CDC COVID-19 Response Team (2020) Severe outcomes among patients with coronavirus disease 2019 (COVID-19)—United States, February 12-March 16, 2020. MMWR Morb Mortal Wkly Rep 69:343-346

3. Istituto Superiore di Sanità Sorveglianza integrata COVID-19 in Italia. https://www.epicentro.iss.it/coronavirus/bollettino. Accessed 7 May 2020

4. Onder G, Rezza G, Brusaferro S (2020) Case-fatality rate and characteristics of patients dying in relation to COVID-19 in Italy. JAMA. https://doi.org/10.1001/jama.2020.4683(Opinion Viewpoint. Published Online: March 23)

5. Lai CC, Shih TP, Ko WC (2020) Severe acute respiratory syndrome coronavirus 2 (SARS-CoV-2) and coronavirus disease-2019 (COVID-19): the epidemic and the challenges. Int J Antimicrob Agents 55(3):105924. https://doi.org/10.1016/j.ijant imicag.2020.105924

6. World Health Organization (2020) Rational use of personal protective equipment for coronavirus disease 2019 (COVID-19). Interim guidance. WHO reference number: WHO/2019-nCov/ IPC PPE_use/2020.1. https://www.who.int/publications-detail/ rational-use-of-personal-protective-equipment-for-coronaviru s-disease-(covid-19)-and-considerations-during-severe-shortages. Accessed 27 Feb 2020

7. Lai J, Ma S, Wang Y, Cai Z (2020) Factors associated with mental health outcomes among health care workers exposed to coronavirus disease 2019. JAMA Network Open 3(3):e203976. https://doi. org/10.1001/jamanetworkopen.2020.3976

8. Yang W, Cao Q, Qin L et al (2020) Clinical characteristics and imaging manifestations of the 2019 novel coronavirus disease (COVID-19): a multi-center study in Wenzhou city, Zhejiang China. J Infect 80:388-393. https://doi.org/10.1016/j. jinf.2020.02.016

9. Wang D, Hu B, Hu C et al (2020) Clinical characteristics of 138 hospitalized patients with 2019 novel coronavirus-infected pneumonia in Wuhan China. JAMA 323(11):1061-1069. https://doi. org/10.1001/jama.2020.1585

10. Chen N, Zhou M, Dong X, Qu J, Gong F et al (2020) Epidemiological and clinical characteristics of 99 cases of 2019 novel coronavirus pneumonia in Wuhan, China a descriptive study. Lancet 395:507-513. https://doi.org/10.1016/S0140-6736(20)30211-7

11. Chen T, Wu D, Chen H, Yan W et al (2020) Clinical characteristics of 113 deceased patients with coronavirus disease 2019: retrospective study. BMJ 368:m1091. https://doi.org/10.1136/bmj. m1091

12. Guan W, Ni Z, Hu Y, Liang W, Ou C, He J, Liu L et al (2020) Clinical characteristics of coronavirus disease 2019 in China. N Engl J Med. https://doi.org/10.1056/NEJMoa2002032(published online)

13. Rodriguez-Morales AJ, Cardona-Ospina JA, Gutiérrez-Ocampoa E et al (2020) Clinical, laboratory and imaging features of
COVID-19: a systematic review and meta-analysis. Travel Med Infect Dis. https://doi.org/10.1016/j.tmaid.2020.101623(article in press)

14. Huang CC, Wang Y, Li X et al (2020) Clinical features of patients infected with 2019 novel coronavirus in Wuhan. Lancet 395:497506. https://doi.org/10.1016/S0140-6736(20)30183-5

15. Cao B, Wang Y, Wen D, Liu W, Wang J, Fan G, Ruan L, Song B et al (2020) A trial of Lopinavir-Ritonavir in adults hospitalized with severe Covid-19. N Engl J Med. https://doi.org/10.1056/ NEJMoa2001282(published online)

16. Zhou F, Yu T, Du R, Fan G, Liu Y, Liu Z, Xiang J et al (2020) Clinical course and risk factors for mortality of adult inpatients with COVID-19 in Wuhan, China: a retrospective cohort study. Lancet 395:1054-1062. https://doi.org/10.1016/S0140 -6736(20)30566-3

17. Tang JW, Tambyah PA, Hui DSC et al (2020) Emergence of a novel coronavirus causing respiratory illness from Wuhan, China. J Infect. https://doi.org/10.1016/j.jinf.2020.01.014(article in press)

18. Liu YC, Liao CH, Hang CF, Chou CC, Lin YR et al (2020) A locally transmitted case of SARS-CoV-2 infection in Taiwan. $\mathrm{N}$ Engl J Med. https://doi.org/10.1056/NEJMc2001573(published online)

19. Lim J, Jeon S, Shin HY, Kim MJ, Seong YM, Lee WJ, Choe KW, Kang YM, Lee B, Park SJ et al (2020) Case of the index patient who caused tertiary transmission of coronavirus disease 2019 in Korea: the application of Lopinavir/Ritonavir for the treatment of COVID-19 pneumonia monitored by quantitative RTPCR. J Korean Med Sci. https://doi.org/10.3346/jkms.2020.35. e79(published online)

20. Lin X, Gong Z, Xiao Z, Xiong J, Fan B, Liu J et al (2020) Novel coronavirus pneumonia outbreak in 2019: computed tomographic findings in two cases. Korean J Radiol. https://doi.org/10.3348/ kjr.2020.0078

21. Silverstein WK, Stroud L, Cleghorn GE, Leis JA et al (2020) First imported case of 2019 novel coronavirus in Canada, presenting as mild pneumonia. Lancet. https://doi.org/10.1016/S0140 $-6736(20) 30370-6$

22. Xu X, Yu C, Zhang L, Luo L, Liu J et al (2020) Imaging features of 2019 novel coronavirus pneumonia. Eur J Nucl Med Mol Imaging. https://doi.org/10.1007/s00259-020-04720-2

23. Wu F, Zhao S, Yu B, Chen YM, Wang W, Song ZG, Hu Y, Tao ZW, Tian JH, Pei YY, Yuan ML, Zhang YL, Dai FH, Liu Y, Wang QM, Zheng JJ, Xu L, Holmes EC, Zhang YZ (2020) A new coronavirus associated with human respiratory disease in China. Nature 579:265-269. https://doi.org/10.1038/s41586-020-2008-3

24. Zhu N, Zhang D, Wang W, Li X, Yang B, Song J, Zhao X, Huang B, Shi W, Lu R, Niu P, Zhan F, Ma X, Wang D, Xu W, Wu G, Gao GF, Tan W (2020) A novel coronavirus from patients with pneumonia in China 2019. N Engl J Med 382(8):727-733. https ://doi.org/10.1056/NEJMoa2001017

25. Holshue ML, DeBolt C, Lindquist S, Lofy KH, Wiesman J, Bruce H, Spitters C, Ericson K, Wilkerson S, Tural A, Diaz G, Cohn A, Fox L, Patel A, Gerber SI, Kim L, Tong S, Lu X, Lindstrom S, Pallansch MA, Weldon WC, Biggs HM, Uyeki TM, Pillai SK (2020) Washington State 2019-nCoV case investigation team first case of 2019 novel coronavirus in the United States. N Engl J Med 382(10):929-936. https://doi.org/10.1056/NEJMoa2001191

26. Shi H, Han X, Zheng C (2020) Evolution of CT manifestations in a patient recovered from 2019 novel coronavirus (2019-nCoV) pneumonia in Wuhan China. Radiol Soc N Am 295(1):20. https ://doi.org/10.1148/radiol.2020200269

27. Hill KJ, Russell CD, Clifford S, Templeton K, Mackintosh CL, Koch O, Sutherland RK et al (2020) The index case of SARS-CoV-2 in Scotland: a case report. J Infect. https://doi. org/10.1016/j.jinf.2020.03.022 
28. Bhatraju PK, Ghassemieh BJ, Nichols M (2020) Covid-19 in critically ill patients in the Seattle region-case series. N Engl J Med. https://doi.org/10.1056/NEJMoa2004500

29. Mao L, Wang M, Chen S et al (2020) Neurological manifestations of hospitalized patients with COVID-19 in Wuhan, China: a retrospective case series study. BMJ. https://doi. org/10.1101/2020.02.22.20026500(Yale preprint)

30. O’Donovan J, Tanveer S, Jones N, Hopkins C (2020) CEBMOxford COVID-19 evidence service. https://www.cebm.net/covid -19/what-is-the-evidence-for-anosmia-loss-of-smell-as-a-clinicalfeature-of-covid-19. Accessed 3 April 2020

31. Verity R, Okell LC, Dorigatti I, Winskill P, Whittaker C, Imai N et al (2020) Estimates of the severity of coronavirus disease 2019: a model-based analysis. Lancet Infect Dis. https://doi.org/10.1016/ S1473-3099(20)30243-7

32. Christian M, Poutanen SM, Loutfy MR, Muller MP, Low DE (2004) Severe acute respiratory syndrome. Clin Infect Dis 38:1420-1427. https://doi.org/10.1086/420743

33. Lee N, Hui D, Wu A, Chan P (2003) A major outbreak of severe acute respiratory syndrome in Hong Kong. N Engl J Med 348:1986-1994. https://doi.org/10.1056/NEJMoa030685

34. Lee N, Hui D, Wu A, Chan P (2003) A major outbreak of severe acute respiratory syndrome in Hong Kong. N Engl J Med 348:1986-1994

35. Punpanich W, Chotpitayasunondh T (2012) A review on the clinical spectrum and natural history of human influenza. Int J Inf Dis 16:e714-e723. https://doi.org/10.1016/j.ijid.2012.05.1025

36. Khandaker G, Dierig A, Rashid $\mathrm{H}$ et al (2011) Systematic review of clinical and epidemiological features of the pandemic influenza A (H1N1) 2009. Influenza Other Respir Viruses 5:148-156. https ://doi.org/10.1111/j.1750-2659.2011.00199.x

37. To KK, Wong SS, Li IW, Hung IF, Tse H, Woo PC, Chan KH, Yuen KY (2010) Concurrent comparison of epidemiology, clinical presentation and outcome between adult patients suffering from the pandemic influenza A (H1N1) 2009 virus and the seasonal influenza A virus infection. Postgrad Med J 86(1019):515-521. https://doi.org/10.1136/pgmj.2009.096206

38. Yang JH, Huang PY, Shie SS et al (1994) Predictive symptoms and signs of laboratory-confirmed influenza A prospective surveillance study of two metropolitan areas in Taiwan. Medicine 44:e1952. https://doi.org/10.1097/MD.0000000000001952

39. Michiels B, Thomas I, Van Royen P, Coenen S (2011) Clinical prediction rules combining signs, symptoms and epidemiological context to distinguish influenza from influenza-like illnesses in primary care: a cross sectional study. BMC Fam Pract 12:4. https ://doi.org/10.1186/1471-2296-12-4

40. Centers for Disease Control and Prevention (CDC) (2013) Estimated influenza illnesses and hospitalizations averted by influenza vaccination-United States, 2012-13 influenza season. MMWR Morb Mortal Wkly Rep 62(49):997-1000

41. Centers for Disease Control and Prevention (CDC) (2013) Estimated influenza illnesses and hospitalizations averted by influenza vaccination-United States, 2012-13 influenza season. MMWR Morb Mortal Wkly Rep 62(49):997-1000

42. WHO Consensus document on the epidemiology of severe acute respiratory syndrome SARS

43. Shi H, Han X, Jiang N et al (2020) Radiological findings from 81 patients with COVID-19 pneumonia in Wuhan, China: a descriptive study. Lancet Infect Dis 20:425-434. https://doi.org/10.1016/ S1473-3099(20)30086-4

44. Mehta P, McAuley DF, Brown M, Sanchez E, Tattersall RS, Manson JJ, HLH Across Speciality Collaboration, UK (2020) COVID19: consider cytokine storm syndromes and immunosuppression. Lancet 395(10229):1033-1034. https://doi.org/10.1016/S0140 $-6736(20) 30628-0(28)$
45. Ruan Q, Yang K, Wang W, Jiang L, Song J (2020) Clinical predictors of mortality due to COVID-19 based on an analysis of data of 150 patients from Wuhan, China. Intensive Care Med 46(5):846-848

46. Lippi G, Plebani M (2020) Procalcitonin in patients with severe coronavirus disease 2019 (COVID-19): a meta-analysis. Clin Chim Acta 505:190-191. https://doi.org/10.1016/j. cca.2020.03.004

47. Lippi G, Lavie CJ, Sanchis-Gomar F (2020) Cardiac troponin I in patients with coronavirus disease 2019 (COVID-19): evidence from a meta-analysis. Prog Cardiovasc Dis. https://doi. org/10.1016/j.pcad.2020.03.001

48. Gao L, Jiang D, Wen X, Cheng X, Sun M, He B, You L (2020) Prognostic value of NT-proBNP in patients with severe COVID-19. Respir Res 21:83. https://doi.org/10.1186/s12931-020-01352-w

49. Soldati G, Smargiassi A, Inchingolo R, Buonsenso D, Perrone T, Briganti DF, Perlini S, Torri E, Mariani A, Mossolani EE, Tursi F, Mento F, Demi L (2020) Is there a role for lung ultrasound during the COVID-19 pandemic? J Ultrasound Med. https://doi. org/10.1002/jum.15284

50. Yang Y, Yang M, Shen C, Wang F (2020) Evaluating the accuracy of different respiratory specimens in the laboratory diagnosis and monitoring the viral shedding of 2019-nCoV infections. BMJ. https://doi.org/10.1101/2020.02.11.20021493(Yale prereview)

51. Zou L, Ruan F, Huang M, Liang L, Huang H, Hong Z, Yu J, Kang M, Song Y, Xia J, Guo Q, Song T, He J, Yen HL, Peiris M, Wu J (2020) SARS-CoV-2 viral load in upper respiratory specimens of infected patients. N Engl J Med 382(12):1177-1179. https://doi. org/10.1056/NEJMc2001737

52. Guo L, Ren L, Yang S, Xiao M, Chang YF, Dela Cruz CS, Wang Y, Wu C, Xiao Y, Zhang L, Han L, Dang S, Xu Y, Yang Q, Xu S, Zhu H, Xu Y, Jin Q, Sharma L, Wang L, Wang J (2020) Profiling early humoral response to diagnose novel coronavirus disease (COVID-19). Clin Infect Dis. https://doi.org/10.1093/cid/ciaa310

53. Zhao J, Yuan Q, Wang H, Liu W, Liao X, Su Y, Wang X, Yuan J, Li T, Li J, Qian S, Hong C, Wang F, Liu Y, Wang Z, He Q, Li Z, He B, Zhang T, Fu Y, Ge S, Liu L, Zhang J, Xia N, Zhang Z (2020) Antibody responses to SARS-CoV-2 in patients of novel coronavirus disease 2019. Clin Infect Dis. https://doi.org/10.1093/ cid/ciaa344

54. Guo L, Dong W, Zhang X, Wu Y, Li Q, Zhou M, Qu J (2019) Clinical features predicting mortality risk in patients with viral pneumonia: the MuLBSTA score. Front Microbiol 10:2752. https ://doi.org/10.3389/fmicb.2019.02752

55. Smith GB, Prytherch DR, Meredith P, Schmidt PE, Featherstone PI (2013) The ability of the national early warning score (NEWS) to discriminate patients at risk of early cardiac arrest, unanticipated intensive care unit admission, and death. Resuscitation 84(4):465-470. https://doi.org/10.1016/j.resuscitat ion.2012.12.016

56. Martín-Rodríguez F, López R et al (2019) Accuracy of national early warning score 2 (NEWS2) in prehospital triage on in-hospital early mortality: a multi-center observational prospective cohort study. Prehosp Disaster Med 34(6):610-618. https://doi. org/10.1017/S1049023X19005041

57. Fernando SM, Fox-Robichaud AE, Rochwerg B, Cardinal P, Seely AJE, Perry JJ, McIsaac DI, Tran A, Skitch S, Tam B, Hickey M, Reardon PM, Tanuseputro P, Kyeremanteng K (2019) Prognostic accuracy of the hamilton early warning score (HEWS) and the national early warning score 2 (NEWS2) among hospitalized patients assessed by a rapid response team. Crit Care 23(1):60. https://doi.org/10.1186/s13054-019-2355-3

Publisher's Note Springer Nature remains neutral with regard to jurisdictional claims in published maps and institutional affiliations. 